\title{
Projeto de cabine de unidade mecânica de auxílio à colheita da cana-de-açúcar (unimac cana) com base na ergonomia
}

\author{
Cab design for a sugar cane harvesting machine based on ergonomics principles
}

\author{
Emanuel Antonio Barreto ${ }^{* *}$ Mauro José Andrade Tereso ${ }^{\mathrm{I}}$ Roberto Funes Abrahão
}

RESUMO

A mecanização da colheita da cana-de-açúcar parece ser o caminho para solução dos problemas decorrentes dos impactos ambientais das queimadas e do trabalho extremamente fatigante na colheita manual. Por outro lado, a mecanização total da colheita levaria milhares de trabalhadores ao desemprego. Para minimizar os impactos ambientais e manter parte desses empregos, a Agricef e a Unicamp estão desenvolvendo o projeto da unidade mecânica de auxílio à colheita da cana-deaçúcar (UNIMAC CANA), baseado em um conceito alternativo representado pela mecanização parcial da colheita, que está em fase de prototipagem. Particularmente, esta pesquisa teve como objetivo o dimensionamento da cabine desse dispositivo e o posicionamento de seus comandos e painéis, com base nas características antropométricas do operador brasileiro. Utilizouse a metodologia projetual orientada pela preocupação com aspectos ergonomicos. As alternativas de projeto geradas através de quadros morfológicos culminaram no dimensionamento da cabine da máquina com sua disposição de comandos, painel e assento, de modo a acomodar o operador de forma segura $e$ confortável. Através de simulação do campo visual do operador, concluiu-se que a cabine, adotando posição móvel em relação à maquina, seria uma opção viável de projeto nos atributos conforto e dirigibilidade.

Palavras-chave: colhedora, colheita de cana-de-açúcar, ergonomia.

\section{ABSTRACT}

Sugar cane harvesting mechanization seems to be the solution for the problems related to the environment impact of sugar cane burning and to facilitate manual harvesting, which also is a extremely hard task. By the other way, full harvest mechanization would lead to a massive unemployment. To minimize environment impact and keep some of the harvesting jobs, Unicamp and Agricefare designing and building a harvesting machine that represents an alternative concept due to it partial harvesting mechanization. The main objective of this research is the design of the cab for this machine and the positioning of its controls and panels, based on the anthropometric characteristics of the brazilian operators. It was used a design methodology with ergonomic emphasis. The alternatives concepts generated by the morphologic boards allowed the dimensioning of the cab and the positioning of panel and controls in order to safely hold the operator. Through the simulation of the operator visual field it was concluded that a movable cab in relation to the machine would be a feasible solution in terms of comfort and drivability.

Key words: harvester, sugar cane harvest, ergonomics.

\section{INTRODUÇÃO}

A partir de 1970, o aumento da demanda de produtos da agricultura foi um dos responsáveis pelo desenvolvimento do setor industrial brasileiro voltado à área agrícola, com o trabalho mecanizado substituindo progressivamente a mão de obra. No Brasil, contudo, nem todas as áreas agrícolas foram contempladas com a introdução e intensificação da mecanização. A cultura da cana-de-açúcar é um exemplo de que ainda há muito que se fazer nesse caminho.

A cana-de-açúcar é um dos principais produtos das exportações brasileiras e ainda constitui uma das opções frequentes de emprego e renda,

IFaculdade de Engenharia Agrícola, Universidade Estadual de Campinas (UNICAMP), Avenida Cândido Rondon, 501, 13083-875, Campinas, SP, Brasil. E-mail: emanuel_antonio@yahoo.com.br. *Autor para correspondência. 
especialmente para os trabalhadores envolvidos nas colheitas. Assim sendo, dentro do processo produtivo, as atividades da colheita manual da cana-de-açúcar são consideradas muito importantes devido ao grande número de trabalhadores envolvidos.

Tendo em vista o desgaste e sofrimento físico dos trabalhadores no corte da cana-de-açúcar, além do aumento da demanda na produção que vêm ocorrendo mundialmente em função da utilização dos biocombustíveis, a necessidade da mecanização da colheita da cana-de-açúcar justificou o projeto Unidade Mecânica de Auxílio à Colheita de Canade-açúcar - UNIMAC CANA (BRAUNBECK \& OLIVEIRA, 2006), desenvolvido pela Unicamp em parceria com a Agricef (Soluções Tecnológicas Inovadoras para a Agricultura).

O dispositivo proposto é baseado em um conceito alternativo representado por uma mecanização parcial da colheita de cana-de-açúcar, composto por uma frente de corte com as funções de efetuar o corte de base e o transporte da massa integral de cana sobre um plano inclinado, seguido por uma célula de trabalho que conta com dois operadores por fileira.

Em duas fileiras no posto de trabalho, esses operadores apanham manualmente os colmos, encaixam-nos em um transportador lateral que os conduz até o despontador e posteriormente até a unidade de limpeza, a qual retira as folhas e lança os colmos inteiros em uma carreta de descarga vertical, onde são armazenados ordenadamente na direção longitudinal de marcha. Finalmente, a carreta efetua a descarga pela abertura de uma porta em seu fundo, permitindo a descida da carga de forma a manter o ordenamento paralelo dos colmos e com isso manter a densidade de carga no carregamento subsequente. A UNIMAC CANA é ilustrada na figura 1.

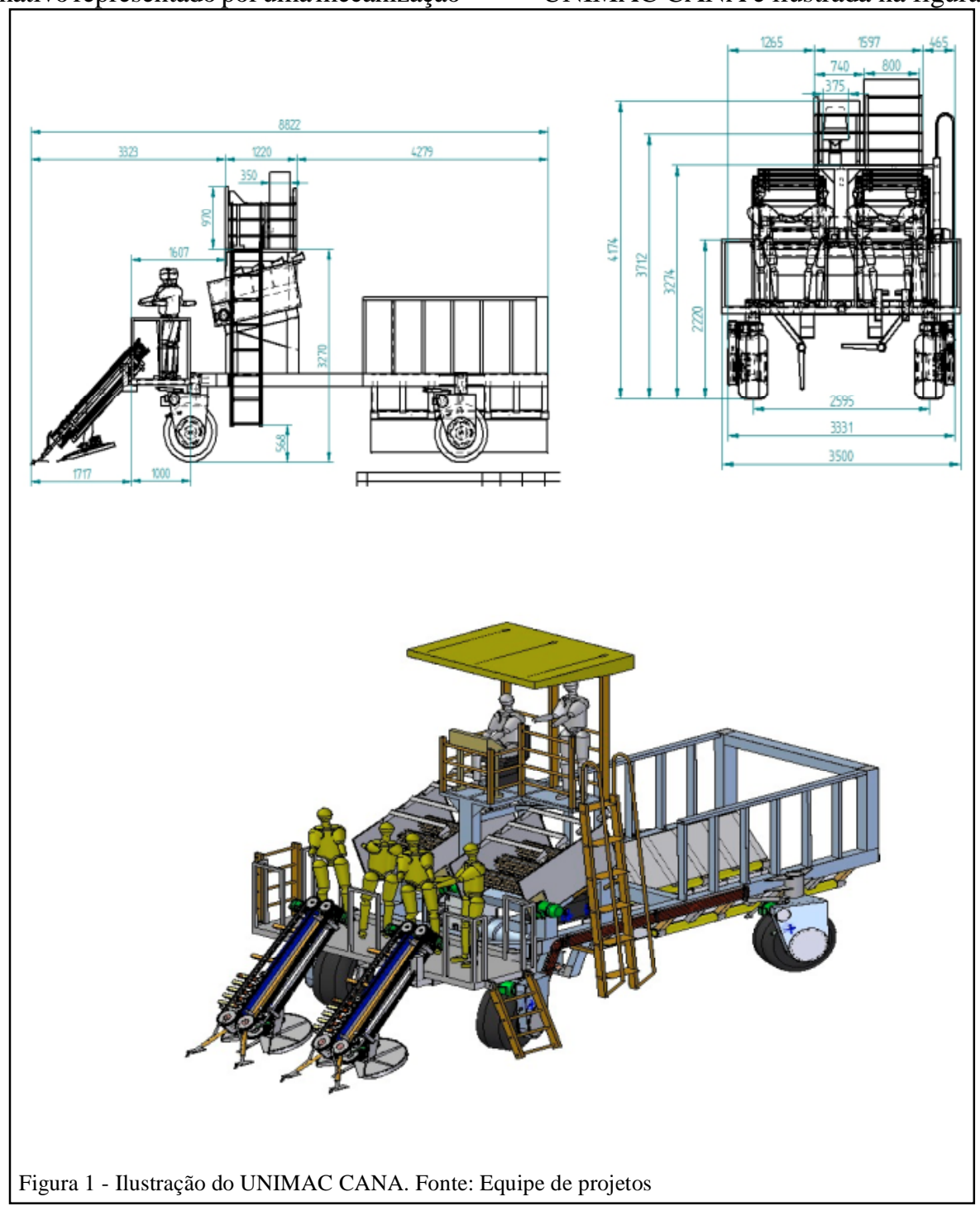

Ciência Rural, v.43, n.5, mai, 2013. 
Esse equipamento procura preservar parte da mão-de-obra da colheita, utilizando 4 trabalhadores na célula de trabalho da frente de corte e mais um operador no controle da máquina. É previsto pela equipe de projeto que a máquina consiga operar em terrenos com declividade de até $50 \%$ e tenha um custo de aquisição de cerca de $30 \%$ do valor de uma colhedora convencional. A produtividade esperada é da ordem de 200ton dia ${ }^{-1}$, já que o corte é feito com a cana inteira e não picada, o que resulta melhor aproveitamento da biomassa.

Por ser uma máquina semi-mecanizada, ainda exige trabalho na frente de corte, além do operador que controla a máquina. A execução da tarefa de controlar e dirigir a máquina em funcionamento, sujeita a vibrações e declives relacionados ao campo de plantio, somado ao fator de exposição à ruídos e intempéries do meio externo do campo de trabalho, trouxe a necessidade da concepção de um habitáculo para o operador isolar-se do meio externo e, ao mesmo tempo, ter total controle das funções exigidas e dos implementos que a máquina opera. Sendo assim, a cabine de controle na UNIMAC CANA não só viabiliza a tarefa de controlar a máquina e seus implementos com melhor dirigibilidade, como também reduz os riscos à saúde do operador.

Para integrar os itens de conforto e segurança ao projeto de uma cabine de controle, a metodologia de CLARK \& CORLETT (1984) se adéqua à concepção de produtos que têm aspectos ergonômicos como relevantes. Essa metodologia, ilustrada na figura 2, consiste em listar e detalhar operações para alcançar o objetivo do sistema, levando-se em conta dados antropométricos e normas regulamentadoras, além de avaliar alternativas de projeto.

Como um projeto de engenharia deve contar com a criação de muitas alternativas, os quadros morfológicos podem ser utilizados para se alcançar essa meta. O método desenvolvido por Fritz Zwicky (DEDINI, 2002) consiste em decompor o problema global em problemas parciais (ou parâmetros do sistema) e identificar o maior número de possíveis alternativas para satisfazer os requisitos do problema. Posteriormente, combinam-se as soluções parciais, obtendo-se várias soluções construtivas para o problema global.

Para que o operador desenvolva uma grande quantidade de tarefas complexas na cabine, com eficiência, segurança e um mínimo de fadiga, devem ser incorporados ao projeto os seguintes fatores: conforto, visibilidade, adequação da temperatura, minimização dos ruídos e vibrações e localização e distribuição adequada dos comandos de operação. Outra questão importante é o posicionamento e as características das vias de acesso ao ponto de operação (FONTANA, 2005).

Com base nessas metodologias e orientado pelas características antropométricas do operador brasileiro, considerando critérios de eficácia, conforto e segurança, com base na ergonomia, este trabalho teve por objetivo dimensionar a cabine de controle da UNIMAC CANA e o posicionamento de seus comandos, seu painel de controle e seu assento.

\section{MATERIAL E MÉTODOS}

As áreas de concepção da cabine de controle consideradas neste trabalho foram: acessibilidade ao posto de trabalho; campo de visão do operador; dimensionamento do espaço de trabalho; controle da máquina; assento do operador; e o isolamento térmico e acústico.

O primeiro passo no projeto da cabine de controle para a UNIMAC CANA foi a criação do maior número possível de alternativas de projeto para cada uma dessas grandes áreas de concepção. Isso foi realizado com a utilização de quadros morfológicos, em que cada uma dessas áreas foi desdobrada em parâmetros mais específicos e, para cada um deles, elaboradas várias alternativas através de sessões de brainstorms, realizadas com a participação das equipes de projetistas.

Com a intenção de selecionar as melhores alternativas, a metodologia de Clark e Corllet foi utilizada de forma a listar e detalhar os requerimentos propostos através de questionários pertinentes a cada área de concepção. Assim, a meta era alcançar o objetivo do sistema, que seria a execução da tarefa de conduzir a máquina pelo operador da cabine com seus atributos de controle e dirigibilidade da melhor forma possível.

As respostas foram obtidas de forma sistemática com base em preceitos da ergonomia e nas normas regulamentadoras. Essas respostas nortearam as escolhas das alternativas mais viáveis de projeto que, depois de compiladas, culminaram no dimensionamento da cabine de controle proposto por este trabalho para a UNIMAC CANA. Foram 


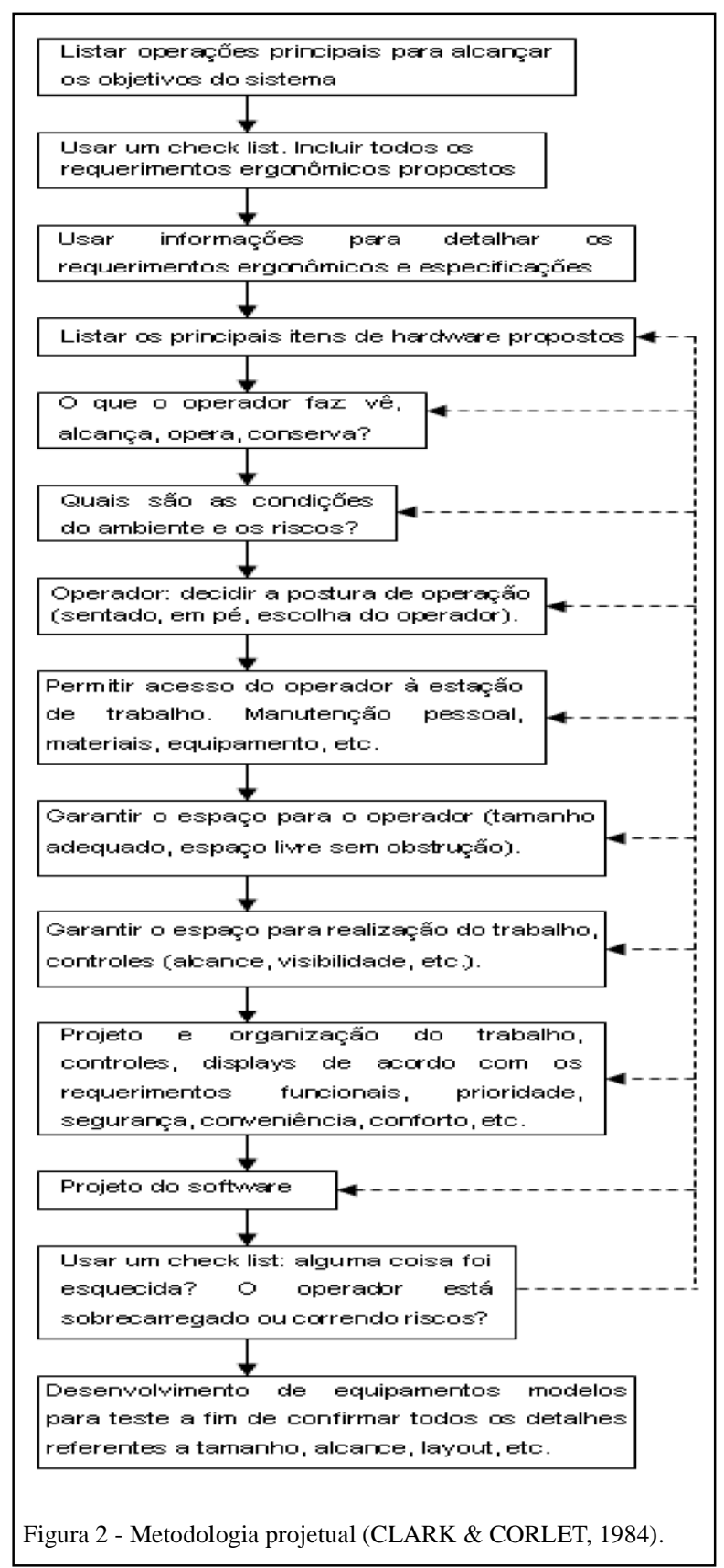

utilizados os dados antropométricos da população brasileira por intermédio do software Ergokit, do Instituto Nacional de Tecnologia (INT, 1995). Para a elaboração dos desenhos e simulações, foram utilizados os softwares Catia V5R19 e DelmiaV5R19.

Com o intuito de dimensionar a cabine para acolher a necessidade da maior parte da população brasileira, os dados antropométricos utilizados consideraram o percentil $95 \%$ adulto masculino, representando o maior usuário, e o percentil $5 \%$ adulto feminino, representando o menor usuário. A figura 3 sintetiza esses dados relativos ao maior e menor usuário. Com os manequins configurados através dessas medidas, foram realizadas as simulações acerca de espaço, alcance e campo visual do operador da cabine, através do software Delmia V5R19, procurando adequar este posto de trabalho para a maior parte da população brasileira.

Foram norteadoras deste trabalho, para o dimensionamento do acesso à cabine, 


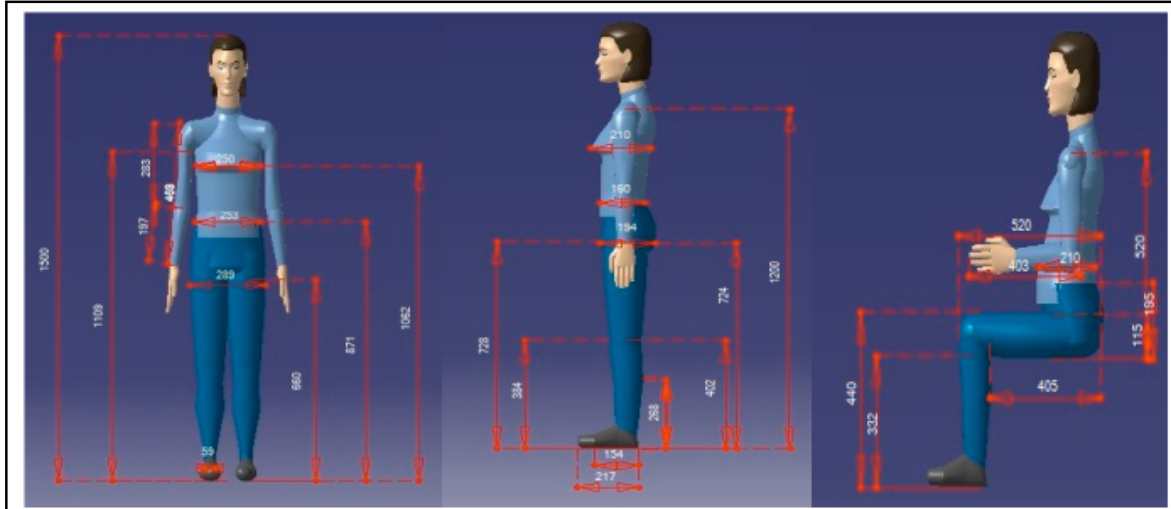

Percentil 5\% feminino

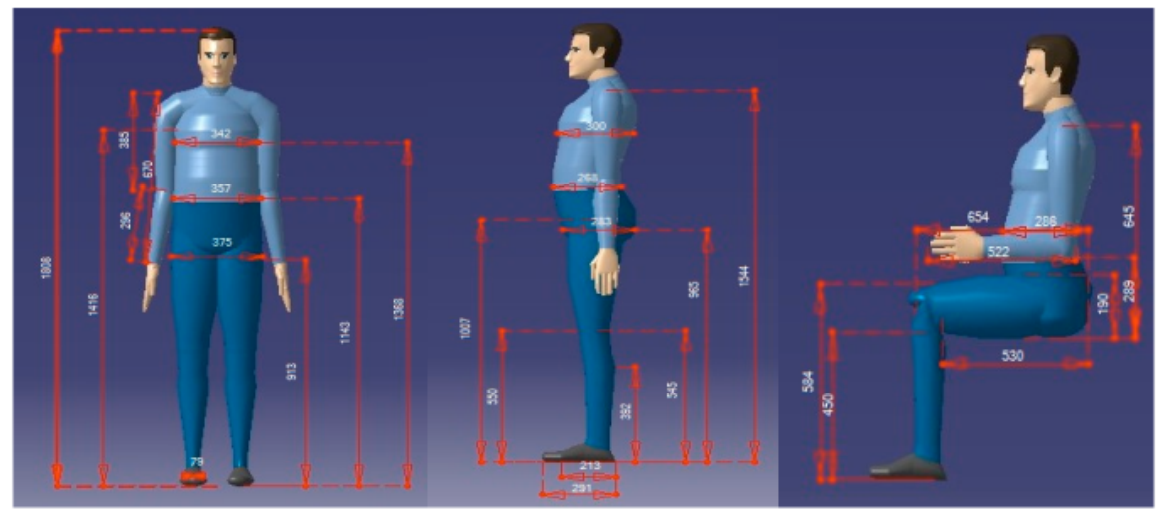

Percentil 95\% masculino

Figura 3 - Medidas antropométricas do menor e do maior usuário.

dimensionamento do habitáculo, projeto do assento e campo visual do operador, as normas brasileiras NBR ISO 4254-1; NBR ISO 4252 e NBR ISO 4253 e as normas técnicas espanholas UNE 68/046 e UNE $68 / 047$.

\section{RESULTADOS E DISCUSSÃO}

Os primeiros resultados deste trabalho de pesquisa foram os quadros morfológicos com suas respectivas alternativas de projetos nas seis grandes áreas de projeto da cabine da UNIMAC CANA. Os resultados também se estendem às perguntas e respostas realizadas pela equipe de projeto com o objetivo de escolher as melhores alternativas de projeto.

Norteadas por esses questionários e suas respostas baseadas em preceitos da ergonomia, as ideias mais viáveis de projeto foram selecionadas. A partir da seleção das melhores alternativas de projeto, identificadas nos quadros morfológicos, foi possível dimensionar a cabine de controle da UNIMAC CANA, o assento do operador com suas respectivas regulagens de altura e profundidade, além do painel de controle fixado na lateral direita do operador, conforme ilustrado pela figura 4.

O layout da cabine e as zonas de alcance do menor e do maior usuário, representados pelo manequim 5\% feminino e $95 \%$ masculino, respectivamente, podem ser vistos na figura 5 . Observa-se que, tanto o maior como o menor usuário tem total alcance do painel de controle lateral sem precisar curvar o tronco, adequando-se perfeitamente ao espaço disponível, devido às regulagens possíveis do assento. 


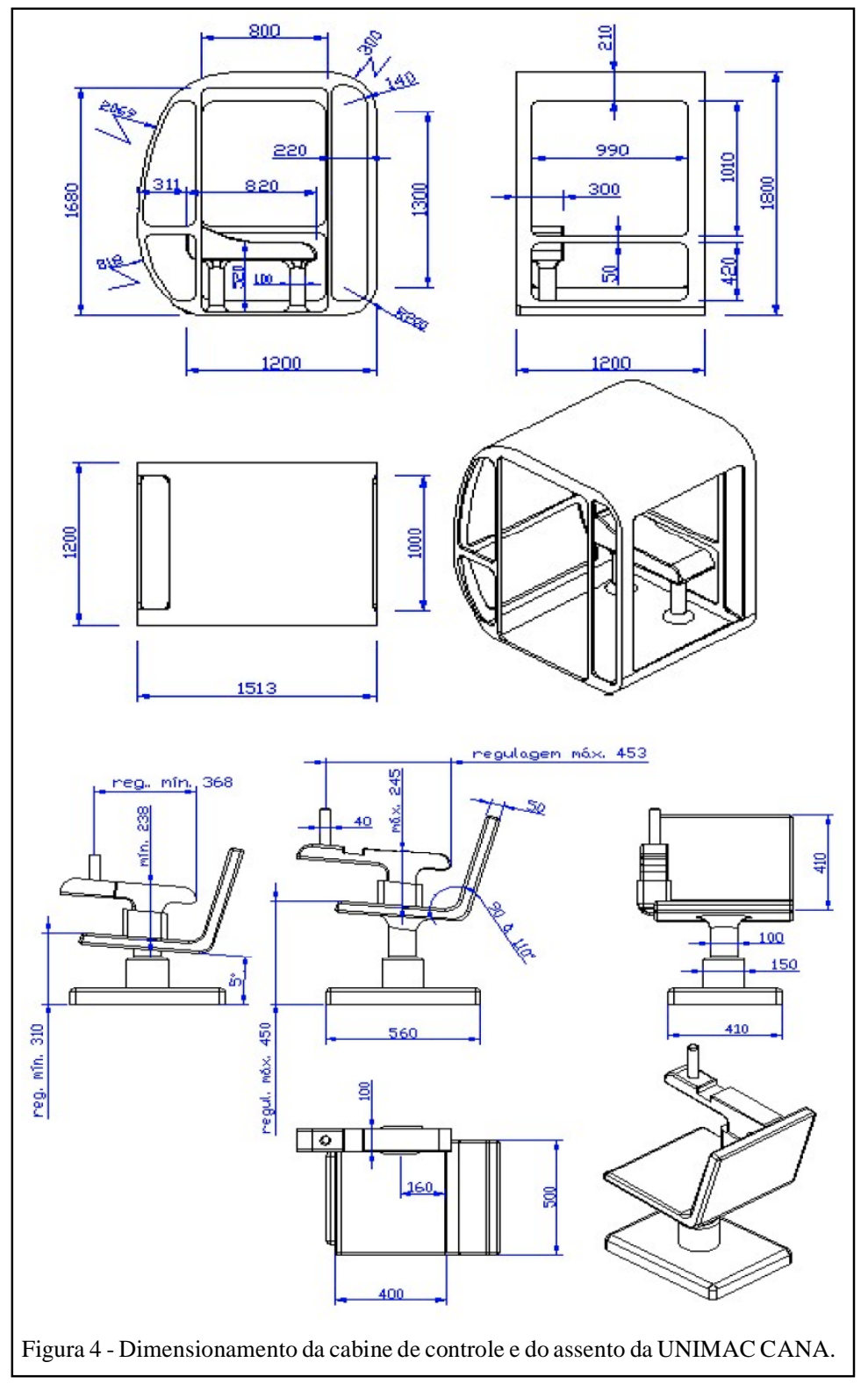

Através de simulação do campo visual do operador e das respostas elaboradas a partir da metodologia, chegou-se a uma solução de uma cabine móvel em relação à máquina, conforme ilustra a figura 6. Nessa concepção, a cabine adota posições móveis, que proporcionam ao operador a possibilidade de uma visão geral da máquina, abrangendo a frente de corte, a célula de trabalho e a caçamba transportadora vertical traseira concomitantemente. A visualização integral da célula de trabalho é de fundamental importância para a segurança dos trabalhadores, uma vez que o operador da cabine necessita tomar as decisões acertadas nas situações de emergência que envolvam riscos ou acidentes nesse posto de trabalho. Com sua diversidade de posições, a cabine móvel também facilita a dirigibilidade da máquina em situações de manobra até o campo de plantio e para o descarregamento de cana-de-açúcar contido na caçamba posterior de descarga. O operador da cabine tem ainda a opção de posicioná-la para operar e conduzir a máquina da forma que lhe for mais conveniente e confortável, em conformidade com os ditames da Ergonomia. 


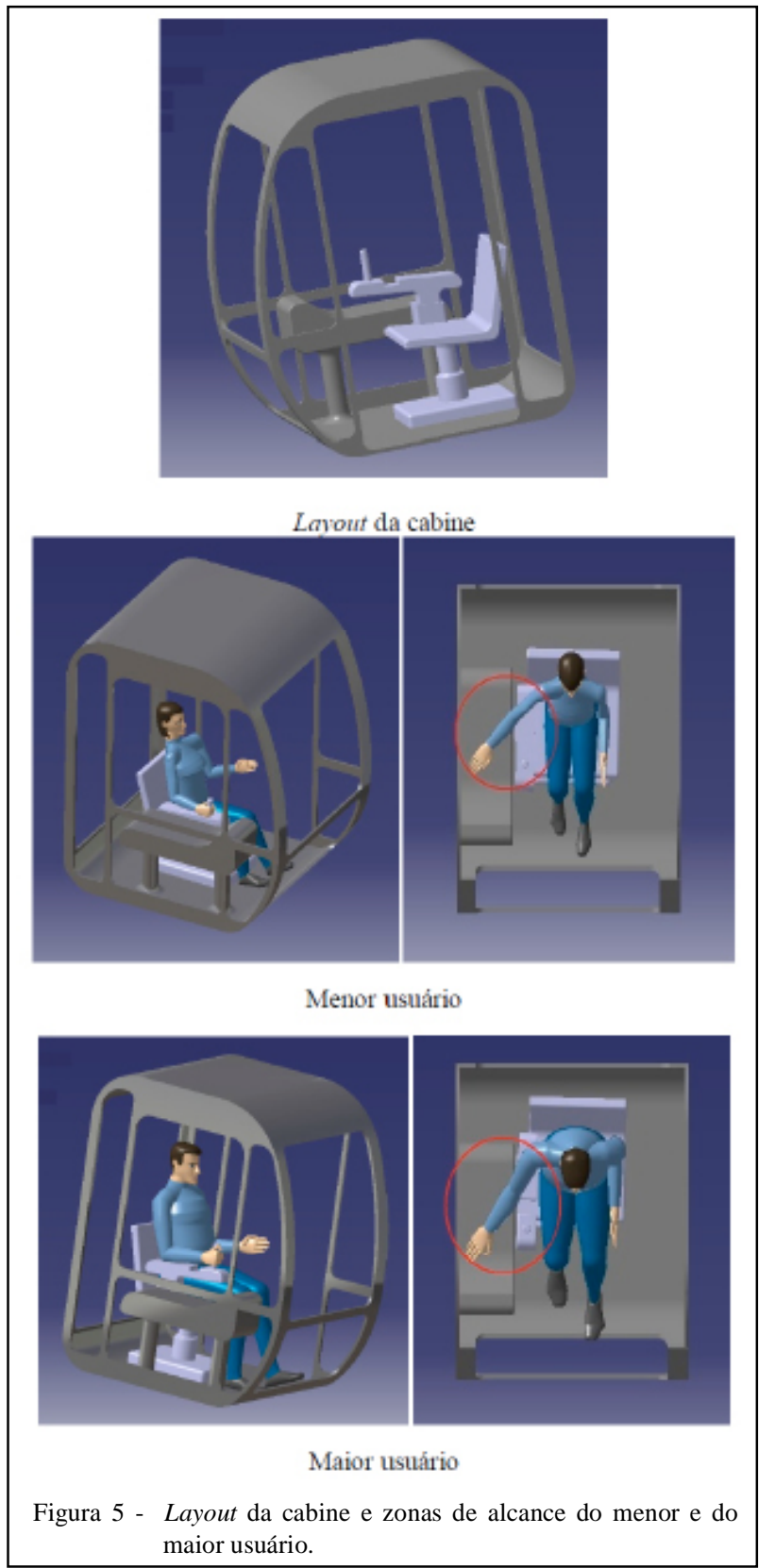

\section{CONCLUSÃO}

Este trabalho atingiu plenamente seu objetivo, com o dimensionamento de um habitáculo para acomodar o operador da UNIMAC CANA de forma confortável e segura, o que abrangeu o posicionamento do assento e do painel de controle da máquina dentro da cabine de controle.

Com a utilização dos softwares Catia V5R19 e Delmia V5R19 e dos manequins antropométricos, as simulações do espaço de trabalho em conjunto com as áreas de alcance e do campo visual do operador permitiram dimensionar e garantir que a cabine acomodasse de forma satisfatória os possíveis operadores, correspondentes à maioria da população brasileira.

Sob o ponto de vista da ergonomia, tendo em vista a maior segurança dos trabalhadores da frente de corte e o conforto do operador da cabine ao conduzir a máquina, este trabalho concluiu que $o$ projeto da cabine móvel é o mais adequado para o equipamento UNIMAC CANA. 


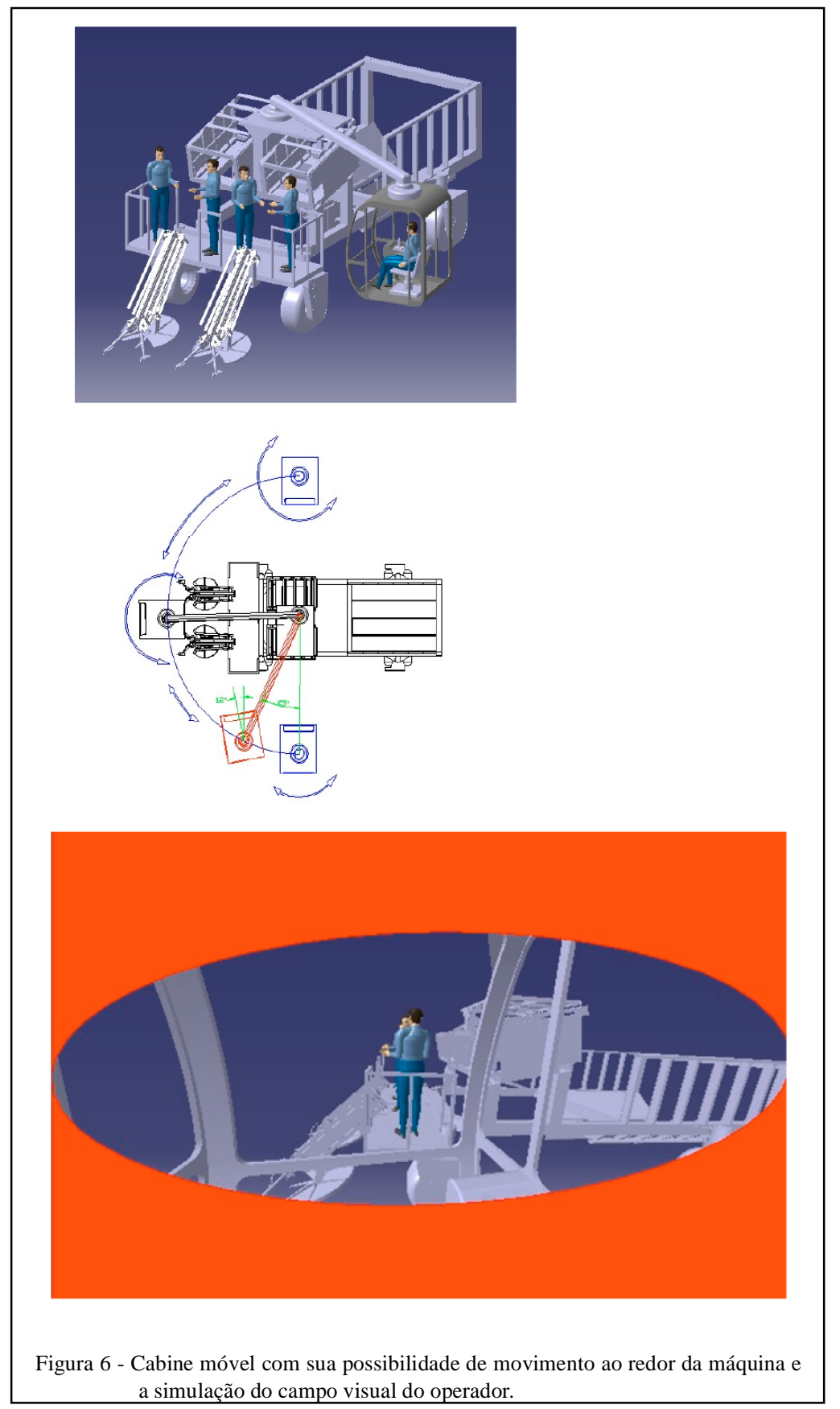

\section{REFERÊNCIAS}

BRAUNBECK, O.A.; OLIVEIRA, J.T.A. Colheita de cana-deaçúcar com auxílio mecânico. Engenharia Agrícola, Jaboticabal, v.26, n.1, p.143-155, jan/abr, 2006. Disponível em: <http://www. scielo.br/pdf/eagri/v26n1/30121.pdf>. Acesso em 23 mar. 2008. doi: 10.1590/S0100-69162006000100032.

DEDINI, F.G. Metodologia e sistemática de projetos. Campinas: Unicamp, 2002. 165p.
CLARK, T.S.; CORLETT, E.N. The ergonomics of workspaces and machines: a design manual. London: Taylor \& Francis, 1984. 128p.

INT (INSTITUTO NACIONAL DE TECNOLOGIA). Manual de aplicação dos dados antropométricos: ERGOKIT. Rio de Janeiro, 1995. 79p.

FONTANA, G. Avaliação ergonômica do projeto interno de cabines de Forwarders e Skidders. 2005. 79f. Dissertação (Mestrado em Máquinas Agrícolas) - Escola Superior de Agricultura Luiz de Queiroz, Universidade de São Paulo, Piracicaba, SP. 